\title{
Diet and the risk of head and neck squamous cell carcinomas in a Syrian population: a case-control study
}

A. Nour, ${ }^{1}$ E. Joury, ${ }^{2,3}$ F. Naja, ${ }^{4}$ W. Hatahet ${ }^{5}$ and A. Almanadili ${ }^{1}$

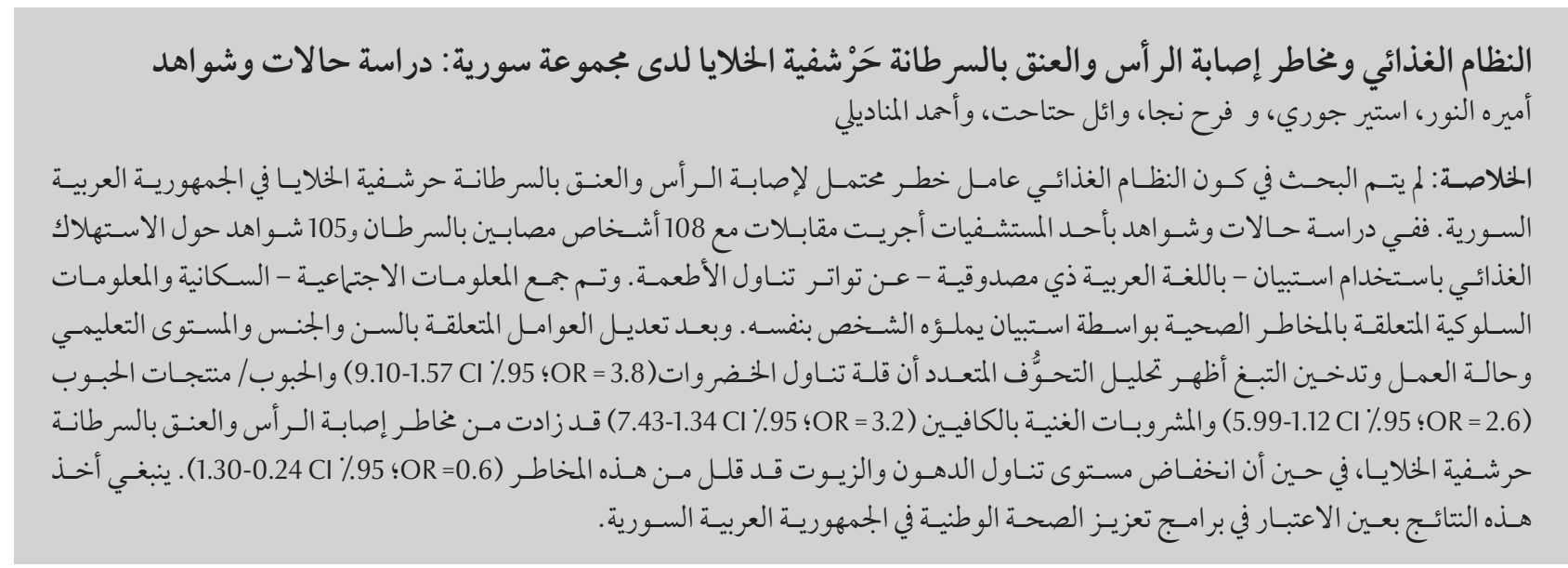

ABSTRACT Diet has not been investigated as a potential risk factor for head and neck squamous cell carcinomas in the Syrian Arab Republic. In a hospital-based, unmatched case-control study 108 people with cancer and 105 controls were interviewed about dietary intake using a validated food frequency questionnaire in Arabic. Sociodemographic and health risk behavioural information were collected by a self-completed questionnaire. Adjusting for age, sex, education level, working status and tobacco smoking, the multiple regression analysis showed that low intake of vegetables (OR 3.8; 95\% Cl: 1.57-9.10), cereal/cereal products (OR 2.6; 95\% Cl: 1.12-5.99) and high-caffeine beverages (OR 3.2; 95\% Cl: 1.34-7.43) increased the risk of head and neck squamous cell carcinomas, whereas a low level of fats and oils intake decreased the risk (OR 0.6; 95\% Cl: 0.24-1.30). These findings should be considered in national health promotion programmes in the Syrian Arab Republic.

\section{Alimentation et risque de carcinome squameux de la tête et du cou dans une population syrienne : étude cas-témoins}

RÉSUMÉ L'alimentation n'avait pas encore été étudiée comme facteur de risque potentiel pour le carcinome squameux de la tête et du cou en République arabe syrienne. Dans une étude cas-témoins non appariés en milieu hospitalier, 108 personnes atteintes d'un cancer et 105 témoins ont été interrogés sur leurs apports alimentaires en recourant à la version en langue arabe d'un questionnaire validé sur la fréquence de consommation alimentaire. Les données sociodémographiques et comportementales en matière de risque pour la santé ont été recueillies à l'aide d'un autoquestionnaire. Après ajustment en fonction de l'âge, du sexe, du niveau d'études et du statut professionnel et tabagique, l'analyse de régression multiple a révélé qu'une faible consommation de légumes (OR 3,8 ; IC à $95 \%$ : 1,57-9,10), de céréales/produits céréaliers (OR 2,6; IC à $95 \%: 1,12-5,99$ ) et de boissons à teneur élevée en caféine (OR 3,2 ; IC à $95 \%$ : 1,34-7,43) augmentaient le risque de carcinome squameux de la tête et du cou, tandis qu'un faible apport en graisses et en huiles réduisait ce risque (OR 0,6 ; IC à $95 \%$ : 0,24 - 1,30). Ces résultats doivent être pris en compte dans les programmes nationaux de promotion de la santé en République arabe syrienne.

'Department of Oral Pathology, Faculty of Dentistry, University of Damascus, Damascus, Syrian Arab Republic (Correspondence to A. Nour: amiiranour@yahoo.com). ${ }^{2}$ Department of Oral Medicine, Faculty of Dentistry, University of Damascus, Damascus, Syrian Arab Republic. ${ }^{3}$ Centre for Oral Growth and Development, Barts and The London School of Medicine and Dentistry, Queen Mary University of London, London, United Kingdom. ${ }^{4}$ Nutrition and Food Sciences Department, Faculty of Agriculture and Food Sciences, American University of Beirut, Beirut, Lebanon. ${ }^{5}$ World Health Organization, Country Office, Iraq.

Received: 09/11/14; accepted: 01/06/15 


\section{Introduction}

Head and neck squamous cell carcinomas (HNSCC) are malignant tumours arising most frequently in the nonkeratinized epithelial tissue of the upper part of the respiratory or gastrointestinal tracts. These tumours develop most commonly during the sixth or seventh decade of life, and significantly less frequently in individuals younger than 40 years (1). Squamous cell carcinoma (SCC) is the most frequent type of head and neck cancer. Tobacco, alcohol and diet are major risk factors $(2,3)$.

The association between dietary intake and the risk of HNSCC has been investigated in a number of studies, whether in relation to single food items or dietary groups $(4,5)$. For example, a low intake of vegetables and fruits, which leads to insufficient folate intake, was associated with an increased risk of HNSCC (6). In contrast, high intake of food rich in fats was associated with an increased risk of HNSCC (7). Generalizing these findings to other populations is not feasible, as dietary intake varies widely across different regions. Thus, local studies should be carried out to investigate the role of local diets in the risk of HNSCC. Should this link be established it will help national public health programmes in shaping dietary recommendations based on the on the role that these dietary groups play in the risk of HNSCC. No study has investigated the association between dietary intake and the risk of HNSCC in the Syrian Arab Republic. Thus, the aim of the current study was to test the association between intake of dietary food groups and the risk of HNSCC in a Syrian population.

\section{Methods}

\section{Study design and sampling}

The current study adopted a hospitalbased, unmatched case-control design. Subjects were selected from all public hospital in Damascus city where patients with HNSCC are referred to receive treatment. These hospitals are: the University of Damascus Dental Hospital, Al-Bayrouny Hospital and AlMojtahed Hospital, which are the only public hospitals in the southern part of the country that provide treatment for cancer patients, including surgical treatment, chemotherapy and/or radiotherapy.

A sample size of 216 individuals was proposed to meet the current study requirements of demonstrating a 2.5 -fold or greater odds ratio (OR) in dietary groups between cases and controls. This calculation set the power of the test at $80 \%$ and the level of significance at 5\%. This sample size calculation allowed for no more than 5\% potential exclusion due to incomplete data.

HNSCC are rare in younger age groups and therefore cases were those aged 40 years and above who had been recently diagnosed with HNSCC and were referred to the above-mentioned hospitals to receive treatment. Cases were approached in their first visit to hospital to receive treatment. Controls were healthy subjects attending the hospitals as the cases' companions (family members/friends living in the same community) and did not suffer from any diet-related diseases such as diabetes or cardiovascular diseases. Both cases and controls were residents in Damascus or suburban Damascus. Subjects with less than 20 natural teeth were excluded as having less than 20 natural teeth might affect diet and nutrition regardless of the medical condition.

Ethical approval for the study was obtained from the research ethics committee of University of Damascus Faculty of Dentistry. Written consent was obtained from each subject. Confidentiality of information collected in the current study was assured. The current study protocol was piloted on 20 participants ( $10 \%$ of the planned sample size).

\section{Data collection and handling}

Data collection took place between October 2011 and April 2012. Dietary data were collected by a face-to-face interview using a validated, semi-quantitative food frequency questionnaire (8). This has been validated on Lebanese/Syrian food items. This questionnaire includes 128 food items and 11 beverages. Subjects were asked to indicate the average frequency of intake of each food item (per month, per week or per day), over the last year. Thereafter, the average weekly intake of each food item was calculated. For example, the frequency of average monthly intake was divided by 4 , whereas the frequency of average daily intake was multiplied by 7. Fooditems were grouped into 9 groups based on the universal classification of MyPyramid food groups $(9,10)$. These 9 groups were dairy, meat/ meat products, vegetables, fruits, cereals/ cereal products, fats and oils, beverages high in caffeine content, beverages low in caffeine content, and sugars and syrups. Each dietary group was dichotomized into high and low levels.

Participants also filled a self-completed questionnaire about their sociodemographic characteristics and health risk behaviours: age, sex, educational level (classified for analysis as post-secondary school education or secondary-school education and below), working status (working or not working) and social class (classified for analysis into professional/non-manual occupation or manual occupation), tobacco smoking (classified for analysis into current/past smoker within the last 10 years or never smoker); and alcohol drinking (current, former or never drinker).

\section{Statistical analysis}

A univariate logistic regression was carried out to test the association between each dietary group and the risk of HNSCC. Next, a multiple logistic regression was performed to confirm the significance of identified associations between dietary groups and the risk of HNSCC, after adjusting for significant 
sociodemographic and health risk behaviours.

\section{Results}

\section{Sociodemographic characteristics and health risk behaviours}

The response rate of the selected sample was $100 \%$. Only 3 controls were excluded due to incomplete data. The sociodemographic characteristics and health risk behaviours of the current study participants are summarized in Table 1. Only 1 participant reported alcohol drinking. The frequency distribution of the cases according to HNSCC site was as follows: 17 (15.7\%) oral, 20 (18.5\%) pharyngeal and 71 (65.7\%) laryngeal cancers.

\section{Univariate analysis of diet $\mathfrak{b}$ HNSCC}

The results of univariate logistic regression are summarized in Table 2 . The risk of HNSCC increased with low levels of intake of vegetables (OR 3.0; 95\% CI: 1.72-5.25; $P<0.001)$ and of cereals/cereal products (OR 2.0; 95\% CI $=1.17-3.4 ; P=0.012$ ) (Table 2). Both low consumption of beverages high in caffeine (OR 2.7; 95\% CI: 1.53-4.63; $P<0.001)$ and low intake of beverages low in caffeine (OR 2.0; 95\% CI: 1.17-3.50; P = $0.011)$ increased the risk of HNSCC (Table 2). In contrast, a low level of fats and oils intake decreased the risk of HNSCC (OR 0.5; 95\% CI: 0.27-0.82; $P=0.008$ ) (Table 2). No significant associations between diary, meat/meat products, fruits, sugars and syrups groups and the risk of HNSCC were found $(P>0.05)$ (Table 2$)$.

Multiple regression analysis of risk factors for HNSCC

After adjusting for age, sex, education level, working status and tobacco smoking, the multiple regression analysis confirmed the significance of the associations between intakes of the abovementioned food groups and the risk of HNSCC, except for beverages low in caffeine content (Table 2). Low levels of intake of vegetables (OR 3.8; 95\% CI: 1.57-9.10), cereal/cereal products (OR 2.6; 95\% CI: 1.12-5.99) and highcaffeine beverages (OR 3.2; 95\% CI: 1.34-7.43) increased the risk of $\mathrm{HN}$ SCC, whereas a low level of fats and oils intake decreased the risk of HNSCC (OR 0.6; 95\% CI: 0.24-1.30).

\section{Discussion}

The current case-control study found that low levels of intake of vegetables, cereal/cereal products and high-caffeine beverages might increase the risk of HNSCC, whereas a low level of fats and oils intake might decrease the risk of HNSCC, providing further evidence,

\begin{tabular}{|c|c|c|c|c|c|}
\hline \multirow[t]{2}{*}{ Variable } & \multicolumn{2}{|c|}{$\begin{array}{l}\text { Controls } \\
(n=105)\end{array}$} & \multicolumn{2}{|c|}{$\begin{array}{c}\text { Cases } \\
(n=108)\end{array}$} & \multirow[t]{2}{*}{$\begin{array}{l}P \text {-value } \\
\left(\chi^{2} \text {-test }\right)\end{array}$} \\
\hline & No. & $\%$ & No. & $\%$ & \\
\hline \multicolumn{6}{|l|}{ Age (years) } \\
\hline $40-50$ & 68 & 64.8 & 36 & 33.3 & \\
\hline $50-60$ & 28 & 26.7 & 36 & 33.3 & \\
\hline $60+$ & 9 & 8.6 & 36 & 33.3 & $<0.001$ \\
\hline \multicolumn{6}{|l|}{ Sex } \\
\hline Male & 39 & 37.1 & 83 & 76.9 & \\
\hline Female & 66 & 62.9 & 25 & 23.1 & $<0.001$ \\
\hline \multicolumn{6}{|l|}{ Education $^{a}$} \\
\hline High level & 67 & 63.8 & 44 & 40.7 & \\
\hline Low level & 38 & 36.2 & 64 & 59.3 & 0.001 \\
\hline \multicolumn{6}{|l|}{ Tobacco smoking } \\
\hline Not smoking & 88 & 83.8 & 33 & 30.6 & \\
\hline Smoking $^{b}$ & 17 & 16.2 & 75 & 69.4 & $<0.001$ \\
\hline \multicolumn{6}{|l|}{ Work status } \\
\hline Working & 55 & 73.1 & 79 & 52.4 & \\
\hline Not working & 50 & 47.6 & 29 & 26.9 & 0.002 \\
\hline \multicolumn{6}{|l|}{ Social class $^{c}$} \\
\hline High & 42 & 52.5 & 36 & 64.3 & \\
\hline Low & 38 & 47.5 & 20 & 35.7 & 0.218 \\
\hline
\end{tabular}

${ }^{a}$ High level included post-secondary-school education (college, university and postgraduate studies) and low level included secondary-school education and below; ${ }^{b}$ Current or past smoker (within the last 10 years); 'Social class was measured by occupation; high social class included professional (non-manual) occupations and low social class included manual occupations. Since those not working $(n=79)$ cannot be classified in this variable, their social class information was considered missing. 


\begin{tabular}{|c|c|c|c|c|c|c|c|}
\hline \multirow[t]{2}{*}{ Variable } & \multirow{2}{*}{$\begin{array}{c}\text { Total } \\
\text { No. }\end{array}$} & \multicolumn{2}{|c|}{ Carcinoma cases } & \multirow{2}{*}{$\begin{array}{l}\text { Unadjusted OR } \\
(95 \% \mathrm{Cl})\end{array}$} & \multirow[t]{2}{*}{$P$-value } & \multirow{2}{*}{$\begin{array}{l}\text { Adjusted OR } \\
(95 \% \mathrm{Cl})^{\mathrm{a}}\end{array}$} & \multirow[t]{2}{*}{$P$-value } \\
\hline & & No. & $\%$ & & & & \\
\hline \multicolumn{8}{|c|}{ Dairy products } \\
\hline High & 107 & 57 & 53.3 & 1 & & 1 & \\
\hline Low & 106 & 51 & 48.1 & $0.8(0.48-1.39)$ & 0.452 & $0.6(0.24-1.30)$ & 0.176 \\
\hline \multicolumn{8}{|c|}{ Meat/meat products } \\
\hline High & 107 & 48 & 44.4 & 1 & & 1 & \\
\hline Low & 106 & 60 & 56.6 & $1.6(0.93-2.75)$ & 0.087 & $0.5(0.20-1.20)$ & 0.119 \\
\hline \multicolumn{8}{|c|}{ Vegetables } \\
\hline High & 109 & 41 & 37.6 & 1 & & 1 & \\
\hline Low & 104 & 67 & 64.4 & $3(1.72-5.25)$ & $<0.001$ & $3.8(1.57-9.10)$ & 0.003 \\
\hline \multicolumn{8}{|l|}{ Fruits } \\
\hline High & 130 & 62 & 47.7 & 1 & & 1 & \\
\hline Low & 83 & 46 & 55.4 & $1.4(0.78-2.37)$ & 0.272 & $2.0(0.88-4.97)$ & 0.095 \\
\hline \multicolumn{8}{|c|}{ Cereals/cereal products } \\
\hline High & 107 & 45 & 42.1 & 1 & & 1 & \\
\hline Low & 106 & 63 & 59.4 & $2.0(1.17-3.48)$ & 0.012 & $2.6(1.12-5.99)$ & 0.026 \\
\hline \multicolumn{8}{|c|}{ Fats and oils } \\
\hline High & 119 & 70 & 58.8 & 1 & & 1 & \\
\hline Low & 94 & 38 & 40.4 & $0.5(0.27-0.82)$ & 0.008 & $0.3(0.10-0.62)$ & 0.002 \\
\hline \multicolumn{8}{|c|}{ Beverages high in caffeine } \\
\hline High & 108 & 42 & 38.9 & 1 & & 1 & \\
\hline Low & 105 & 66 & 62.9 & $2.7(1.53-4.63)$ & 0.001 & $3.2(1.34-7.43)$ & 0.008 \\
\hline \multicolumn{8}{|c|}{ Beverages low in caffeine } \\
\hline High & 111 & 47 & 42.3 & 1 & & 1 & \\
\hline Low & 102 & 61 & 59.8 & $2.0(1.17-3.50)$ & 0.011 & $1.0(0.44-2.31)$ & 0.980 \\
\hline \multicolumn{8}{|c|}{ Sugars and syrups } \\
\hline High & 109 & 55 & 50.5 & 1 & & 1 & \\
\hline Low & 104 & 53 & 51.0 & $1(0.60-1.75)$ & 0.942 & $0.6(0.26-1.32)$ & 0.195 \\
\hline
\end{tabular}

${ }^{a}$ Adjusted for age, sex, education level, working status and tobacco smoking. $O R=$ odds ratio; $C I=$ confidence interval.

therefore, for the important role of diet in HNSCC.

The role of low levels of vegetables intake in the risk of HNSCC found in the current study is in agreement with Levi et al.'s study in Switzerland that showed a linkage between low vegetable intake and high risk of oral and pharyngeal cancer (11). Previous studies in China and Italy on vegetable and fruit intake and risk of oral and pharyngeal carcinomas have consistently reported protective effects for these plant foods $(12,13)$. De Stefani et al. in Uruguay suggested that fruits are more protective than vegetables (14). In our study, the greatest reduction in risk was associated with a high intake of fresh vegetables (adjusted OR 3.8; 95\% CI: 1.57-9.10). With regard to possible mechanism(s) of action of vegetables, it is tempting to attribute the protective effect of these foods to their high content of vitamins and bioactive substances, particularly vitamin $\mathrm{C}$, carotenoids and flavonols (15). The lack of a significant role of fruits in the risk of HNSCC in the current study population might be attributed to the general high intake of this dietary group in the Syrian population.

In the present study, high intake of beverages low in caffeine (such as green/herbal teas) was associated with a protective effect. The protective effect of herbal teas has been attributed to an anti-proliferative effect and induction of apoptosis. Other suggested mechanisms relate to the antioxidative properties, the inhibition of lipoxygenase and cyclooxygenase, a rapid decrease of prostaglandin E2 and the inhibition of angiogenesis (16). The significance of beverages low in caffeine did not persist in the multiple regression model, suggesting a possible confounding effect of one or more of the sociodemographic and health risk behavioural variables in the model. 
It is worth mentioning that there may be a "cleansing" effect of some of the plants and non-alcoholic beverages, as suggested previously by Franceschi et al. in Italy. They investigated the frequency of intake of a selected number of indicator foods on the risk of cancer of the mouth in smokers and non-smokers and suggested that the cleansing effect of some food, namely some vegetables and nonalcoholic drinks, may reduce the risk of mouth cancer (17). The role of vegetables in cleansing carcinogens inside the oral cavity could be attributed to their rich content of dietary fibres (18).

The role of low levels of cereals/ cereal products intake in the risk of $\mathrm{HN}$ SCC, found in the present study, is in line with Lucenteforte et al.'s findings in Italy (4). Grains, particularly whole grains, are rich in dietary fibres, resistant starch, oligosaccharides and antioxidants, including trace minerals, all of which are considered protective against cancer. In addition, whole grains are important sources of phytoestrogens that have hormonal effects related to cancer protection (19-21).

The correlation between high fat intake and the risk of HNSCC identified in the present study is similar to a study conducted in the Islamic Republic of Iran in which high fat intake was highly positively associated with the risk of gastric cancer (22). The excess energy intake from high-fat diet elevates the intravascular level of insulin and energy substrate. The latter (i.e. the increased levels of intravascular insulin and intracellular energy stores) would, in turn, stimulate cell-signalling pathways, leading to an increased proliferation with defective cell cycle control, resulting in development of cancer (23).
The correlation between reduced risk of cancer and higher intake of high caffeine drinks has been established. These drinks, such as coffee, have been shown to have anti-tumour, anti-angiogenic and antioxidant properties. Coffee has an effect on cell proliferation and the cell-cycle process. Caffeine was found to enhance the cytotoxic activities of ionizing radiation in human leukaemia cells and decrease the level of apoptosis inhibitor (24).

Other dietary groups, namely dairy, meat/meat products and sugars and syrups, were not significantly associated with the risk of HNSCC in the present study. The findings reported in the literature are inconsistent regarding the role of these dietary groups and upper aerodigestive tract cancers (25).

One of the limitations of the current case-control study is possible recall bias. Yet efforts were exercised to minimize such a bias by blinding the participants to the current study's specific aim. Another potential limitation was interviewer bias. Nevertheless, the training and calibration the interviewer received would have largely minimized this potential bias. As in any other observational analytical study, causality between diet and the risk of HNSCC cannot be established. Analysing the data from this study is not an easy task keeping in mind that food in the Middle East is very complex and the culinary culture is very well-rooted and any food item is likely to be a mix of many individual food groups. While the study tried to stratify the intake according to the food groups, some overlap between the groups will exist. Nevertheless, the results of our study are in line with those of previous studies and this gives us confidence in the methodology and the food categorization used.

As a practical dietary guide based on the current study findings, increasing the intake of vegetables, cereals/ cereal products and caffeinated beverages, and decreasing the intake of fats and oils, might decrease the risk of HNSCC.

More studies investigating the role of diet in the risk of HNSSC in the Eastern Mediterranean Region (EMR) are needed. Developing and validating food frequency questionnaires for research purposes are also needed in other countries in the EMR. Although Syrian and Lebanese diets are very similar, this is not the case for other EMR countries, such as those in the Gulf Cooperation Council. Randomized controlled trials to investigate the role of decreasing and/or increasing the intake of dietary groups in preventing HNSCC might establish a causal relationship between such dietary groups and the risk of HNSCC.

In conclusion, low levels of intake of vegetables, cereal/cereal products and high-caffeine beverages might increase the risk of HNSCC, whereas a low level of fats and oils intake might decrease the risk of HNSCC. These findings should be considered in national health promotion programmes in the Syrian Arab Republic.

\section{Acknowledgements}

The authors wish to thank all the subjects who participated in the current study.

Funding: This study was funded by the University of Damascus.

Competing interests: None declared.

\section{References}

1. Gawecki W, Szyfter K, Szyfter W. [The role of exogenous and epidemiological factors in etiology of squamous cell carcinoma of the head and neck in young adults]. Otolaryngol Pol. 2007;61(1):52-7. PMID:17605419
2. Shahrour MS. [Cancer of the jaw and oral cavity in the Syrian Arab Republic: an epidemiological study] [in Arabic]. East Mediterr Health J. 2005 May;11(3):273-86. PMID:16602446 
3. Toporcov TN, Tavares GE, Rotundo LD, Vaccarezza GF, Biazevic MG, Brasileiro RS, et al. Do tobacco and alcohol modify protective effects of diet on oral carcinogenesis? Nutr Cancer. 2012;64(8):1182-9. PMID:23163847

4. Lucenteforte E, Garavello W, Bosetti C, La Vecchia C. Dietary factors and oral and pharyngeal cancer risk. Oral Oncol. 2009 Jun;45(6):461-7. PMID:18990606

5. Li K, Yu P. Food groups and risk of esophageal cancer in Chaoshan region of China: a high-risk area of esophageal cancer. Cancer Invest. 2003 Apr;21(2):237-40. PMID:12743989

6. Suzuki T, Matsuo K, Hasegawa Y, Hiraki A, Wakai K, Hirose K, et al. One-carbon metabolism-related gene polymorphisms and risk of head and neck squamous cell carcinoma: case-control study. Cancer Sci. 2007 Sep;98(9):1439-46. PMID:17596206

7. Edefonti V, Hashibe M, Ambrogi F, Parpinel M, Bravi F, Talamini $\mathrm{R}$, et al. Nutrient-based dietary patterns and the risk of head and neck cancer: a pooled analysis in the International Head and Neck Cancer Epidemiology consortium. Ann Oncol. 2012 Jul;23(7):1869-80. PMID:22123733

8. Nasreddine L, Hwalla N, Sibai A, Hamzé M, Parent-Massin D. Food consumption patterns in an adult urban population in Beirut, Lebanon. Public Health Nutr. 2006 Apr;9(2):194-203. PMID:16571173

9. Britten P, Lyon J, Weaver CM, Kris-Etherton PM, Nicklas TA, Weber JA, et al. MyPyramid food intake pattern modeling for the Dietary Guidelines Advisory Committee. J Nutr Educ Behav. 2006 Nov-Dec;38(6) Suppl:S143-52. PMID:17116592

10. Britten P, Marcoe K, Yamini S, Davis C. Development of food intake patterns for the MyPyramid food guidance system. J Nutr Educ Behav. 2006 Nov-Dec;38(6) Suppl:S78-92. PMID:17116598

11. Levi F, Pasche C, La Vecchia C, Lucchini F, Franceschi S, Monnier $\mathrm{P}$. Food groups and risk of oral and pharyngeal cancer. International journal of cancer Int J Cancer. 1998 Aug 31;77(5):705-9. PMID:9688303

12. Zheng T, Boyle P, Willett WC, Hu H, Dan J, Evstifeeva TV, et al. A case-control study of oral cancer in Beijing, People's Republic of China. Associations with nutrient intakes, foods and food groups. Eur J Cancer B Oral Oncol. 1993 Jan;29B(1):45-55. PMID:8180577

13. La Vecchia C, Negri E, D'Avanzo B, Boyle P, Franceschi S. Dietary indicators of oral and pharyngeal cancer. Int J Epidemiol. 1991 Mar;20(1):39-44. PMID:2066242

14. De Stefani E, Boffetta P, Ronco AL, Correa P, Oreggia F, DeneoPellegrini $\mathrm{H}$, et al. Dietary patterns and risk of cancer of the oral cavity and pharynx in Uruguay. Nutr Cancer. 2005;51(2):132-9. PMID:15860434

15. Potter JD, Steinmetz K. Vegetables, fruit and phytoestrogens as preventive agents. IARC Sci Publ. 1996; (139):61-90. PMID:8923020

16. Yang CS, Yang GY, Chung JY, Lee MJ, Li C. Tea and tea polyphenols in cancer prevention. Adv Exp Med Biol. 2001;492:39-53. PMID:11480674

17. Franceschi S, Barra S, La Vecchia C, Bidoli E, Negri E, Talamini R. Risk factors for cancer of the tongue and the mouth. A case-control study from northern Italy. Cancer. 1992 Nov 1;70(9):2227-33. PMID:1394055

18. Pelucchi C, Talamini R, Negri E, Levi F, Conti E, Franceschi S, et al. Folate intake and risk of oral and pharyngeal cancer. Ann Oncol. 2003 Nov;14(11):1677-81. PMID:14581278

19. Slavin JL. Mechanisms for the impact of whole grain foods on cancer risk. J Am Coll Nutr. 2000 Jun;19(3) Suppl:300S-7S. PMID:10875601

20. Skeie G, Braaten T, Olsen A, Kyrø C, Tjønneland A, Nilsson LM, et al. Whole grain intake and survival among Scandinavian colorectal cancer patients. Nutr Cancer. 2014;66(1):6-13. PMID:24274588

21. Schatzkin A, Park Y, Leitzmann MF, Hollenbeck AR, Cross AJ. Prospective study of dietary fiber, whole grain foods, and small intestinal cancer. Gastroenterology. 2008 Oct;135(4):1163-7. PMID:18727930

22. Somi MH, Mousavi SM, Naghashi S, Faramarzi E, Jafarabadi MA, Ghojazade $M$, et al. Is there any relationship between food habits in the last two decades and gastric cancer in NorthWestern Iran? Asian Pac J Cancer Prev. 2015;16(1):283-90. PMID:25640366

23. Bruce WR, Giacca A, Medline A. Possible mechanisms relating diet and risk of colon cancer. Cancer Epidemiol Biomarkers Prev. 2000 Dec;9(12):1271-9.PMID:11142411

24. Rossi T, Gallo C, Bassani B, Canali S, Albini A, Bruno A. Drink your prevention: beverages with cancer preventive phytochemicals. Pol Arch Med Wewn. 2014;124(12):713-22. PMID:25490889

25. Bravi F, Edefonti V, Randi G, Ferraroni M, La Vecchia C, Decarli A. Dietary patterns and upper aerodigestive tract cancers: an overview and review. Ann Oncol. 2012 Dec;23(12):3024-39. PMID:22967993 